\title{
Changes in Brain GnRH after Olfactory Tract Section in Female Goldfish
}

\author{
Myung-Hee Kim, Makito Kobayashi, ${ }^{\dagger}$ and Katsumi Aida \\ Department of Fisheries, Faculty of Agriculture, The University of Tokyo, \\ Bunkyo, Tokyo 113, Japan
}

(Received December 1, 1994)

Two types of GnRH contents, salmon type (sGnRH) and chicken-II type (cGnRH-II) were measured in the brain of goldfish after olfactory tract section in order to characterize the effects of the olfactory tract section on brain GnRH content and to determine an appropriate time for use of the olfactory tract-sectioned fish after the operation. Brain sGnRH contents started to decrease at 7 days after the operation, reached low levels by 14 days, and were decreased up to 56 days after the operation. Brain cGnRH-II contents showed no clear changes up to 56 days after the operation. The results indicate that it is appropriate to use olfactory tract-sectioned fish 14 days or later after the operation when the influence of GnRH of terminal nerve origin has been removed.

Key words: goldfish, gonadotropin-releasing hormone, GnRH, terminal nerve, olfactory tract section

Gonadotropin-releasing hormone (GnRH) is a decapeptide which was originally isolated from pig and sheep hypothalami and functions in the release of gonadotropin (GTH) from the pituitary gland. ${ }^{1,2)}$ To date, eight different types of GnRH have been identified in vertebrate brain extracts, which constitute a family of structurally related decapeptides. ${ }^{1,2)}$ Recent studies have shown that more than one type of GnRH exist in the brain of teleosts, ${ }^{1,2)}$ and GnRH neurons are found not only in the hypothalamic region but also in extrahypothalamic regions of the brain. ${ }^{3)}$ These results led us to consider whether all of the brain GnRHs function as regulators of GTH release. If not, then which population of GnRH neurons and which type of GnRH directly regulates GTH release in teleosts.

In goldfish Carassius auratus, two types of GnRH, salmon type (sGnRH) and chicken-II type (cGnRH-II), have been chromatographically and immunologically identified in the brain and pituitary gland. ${ }^{4,5)} \mathrm{A}$ more recent immunocytochemical study of the goldfish has revealed that sGnRH cell bodies are localized in the olfactory bulb (the terminal nerve, TN), ventral telencephalon, preoptic area, and anterior hypothalamus. ${ }^{6}$ Cell bodies containing cGnRH-II were found in the same areas as those of sGnRH and also in the midbrain tegmentum. ${ }^{\text {. Salmon }}$ GnRH and cGnRH-II fibers are widely distributed in the brain and pituitary. ${ }^{6}$ Among the GnRH populations, our studies using olfactory tract-sectioned goldfish have shown that GnRH neurons of the TN-origin are not involved in mediating gonadal maturation although sGnRH of the TN-origin comprises most of the brains' sGnRH. ${ }^{5,7)}$ The olfactory tract section procedure blocks the axonal transport of GnRH from the TN cells to other regions of the brain. Gonadal development of treated individuals was not affected despite a decreased $s G n R H$ content in the brain. These findings suggest that GTH secretion in the goldfish is primarily regulated by GnRH systems other than the TN system. Therefore, olfactory tract-sectioned goldfish can be considered as a good model to investigate causal relationships between brain GnRH activity and GTH release.

In the present study, we examined changes in GnRH contents in the brain, plasma GTH levels, and gonadal size after olfactory tract section in order to further characterize the effects of olfactory tract section in the female goldfish. In particular, we focused on determining the appropriate time that olfactory tract-sectioned fish could be used after the operation.

\section{Materials and Methods}

\section{General Protocols}

Sexually immature females, weighing 10 to $20 \mathrm{~g}$ were purchased from a commercial source in May. In June, fish were transferred to a $1000 l$ experimental tank with water temperature and photoperiod set at $18^{\circ} \mathrm{C}$ under $14 \mathrm{~L} 10 \mathrm{D}$ (lights on at 4:00 h), respectively. Fish were fed with a commercial trout pellet ad libitum on a daily basis.

Fish were classified into three groups; intact $(n=40)$, sham operated $(n=41)$, and olfactory tract-sectioned (OTX, $n=41$ ). Olfactory tract sections and sham operations were conducted as described by Kobayashi et al. ${ }^{5,7}$ Groups of fish ( $n=4-7$ for each group) from each treatment were sampled before treatments began (i.e. initial control) and subsequently at $3,7,14,21,28$, and 56 days after the operation.

At each sampling, fish were first anesthetized with $0.02 \%$ MS-222 (Sigma Chemical, U.S.A.), body weights were measured, and blood samples were taken from the caudal vasculature with a heparinized needle and syringe. Plasma was separated by centrifuging at $1500 \mathrm{~g}$, and

\footnotetext{
${ }^{\dagger}$ To whom offprint request should be addressed.
} 
stored at $-20^{\circ} \mathrm{C}$. The ovaries were dissected and weighed to determine the gonadosomatic index (GSI). Fish were then decapitated, and the brains and pituitary glands were collected. The brains were dissected into six parts (olfactory bulbs, telencephalon, hypothalamus, optic tectum-thalamus, cerebellum, medulla oblongata; Fig. 1). The tissues were weighed and then frozen on dry ice and stored at $-20^{\circ} \mathrm{C}$ until assayed. For GnRH measurements, the tissues were treated as described previously. ${ }^{5,7)}$

\section{Radioimmunoassays}

Salmon GnRH and cGnRH-II were measured by specific radioimmunoassay systems that have been characterized and described previously. ${ }^{5,8)}$ Plasma GTH was measured using a silver carp GTH radioimmunoassay system that also has been characterized and described previously. ${ }^{5,9)}$

\section{Statistics}

Difference of means among groups was analyzed by ANOVA and Duncan's test with raw or log-transformed data.

\section{Results}

Body Weight, GSI, and Plasma GTH Levels

No difference could be detected in body weight, GSI,

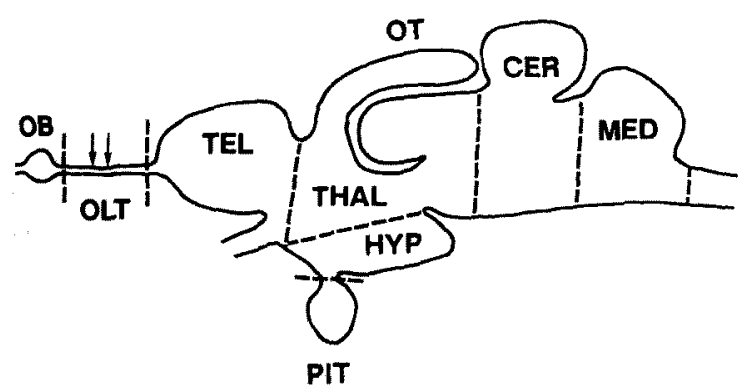

Fig. 1. Schematic diagram of a sagittal section of goldfish brain showing sites of severance of the olfactory tracts (arrows) and areas of the brain used to determine GnRH content.

OLT, olfactory tracts; OB, olfactory bulbs; TEL, telencephalon, including preoptic area; OT-THAL, optic tectum-thalamus, including midbrain tegmentum; CER, cerebellum; MED, medulla oblongata; PIT, pituitary.
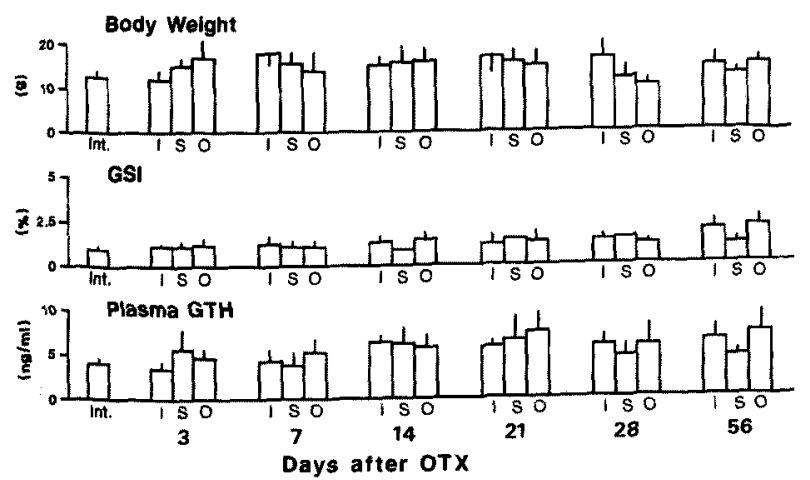

Fig. 2. Changes in body weight, gonadosomatic index (GSI), and plasma gonadotropin (GTH) levels in initial control (Int.), intact (I), sham-operated (S), and olfactory tract-sectioned female goldfish $(O)$. Each column represents the mean and SEM. and plasma GTH levels among the intact, sham-operated, and OTX fish during the experimental period (Fig. 2).

\section{Brain and Pituitary GnRH Contents}

The sGnRH contents did not differ among the three treatment groups three days after the operation (Fig. 3). In OTX fish, sGnRH contents in the hypothalamus started to decrease seven days after the operation: compared to levels of intact and sham-operated fish $(p<0.05)$. At 14 days after the operation in OTX fish, sGnRH contents in discrete areas of the brain (i.e. telencepahlon, optic tectum-thalamus, cerebellum, and medulla oblongata) except for the olfactory bulbs, reached significantly low levels $(p<0.05)$ compared to levels of intact and sham-operated fish, and were decreased up to 56 days after the operation. Shamoperated fish also exhibited a significant decrease $(p<0.05)$ in sGnRH compared to levels of intact fish after the operation. Salmon GnRH contents in the olfactory bulbs and pituitary exhibited large variations and no clear tendencies in the three groups.

No obvious changes could be detected in cGnRH-II in the brain and pituitary after the operation in the three groups (Fig. 4).
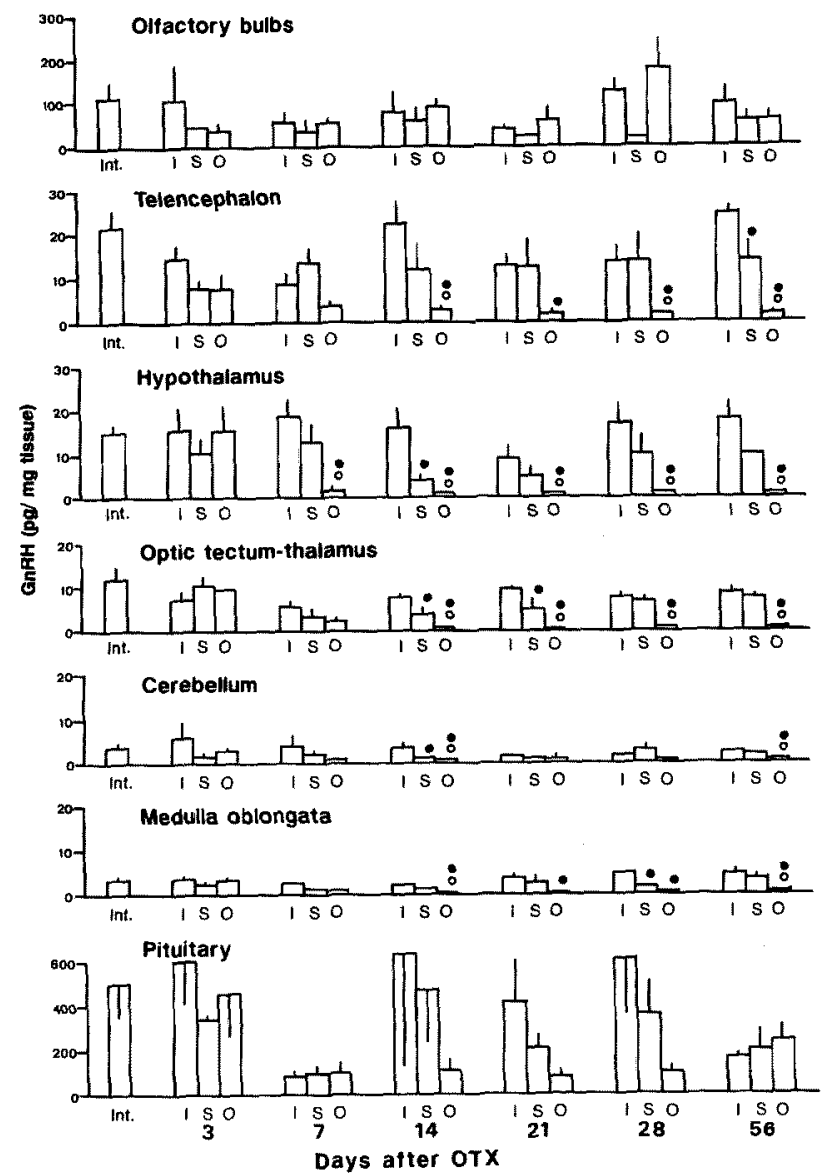

Fig. 3. Changes in $s$ GnRH concentrations in discrete areas of the brain after olfactory tract section in female goldfish.

Int., initial control; 1 , intact; $S$, sham-operated fish; $O$, olfactory tract-sectioned fish. Each column represents the mean and SEM. Difference compared to intact fish; $O$, compared to sham-operated fish. Level of significance; $p<0.05$. 

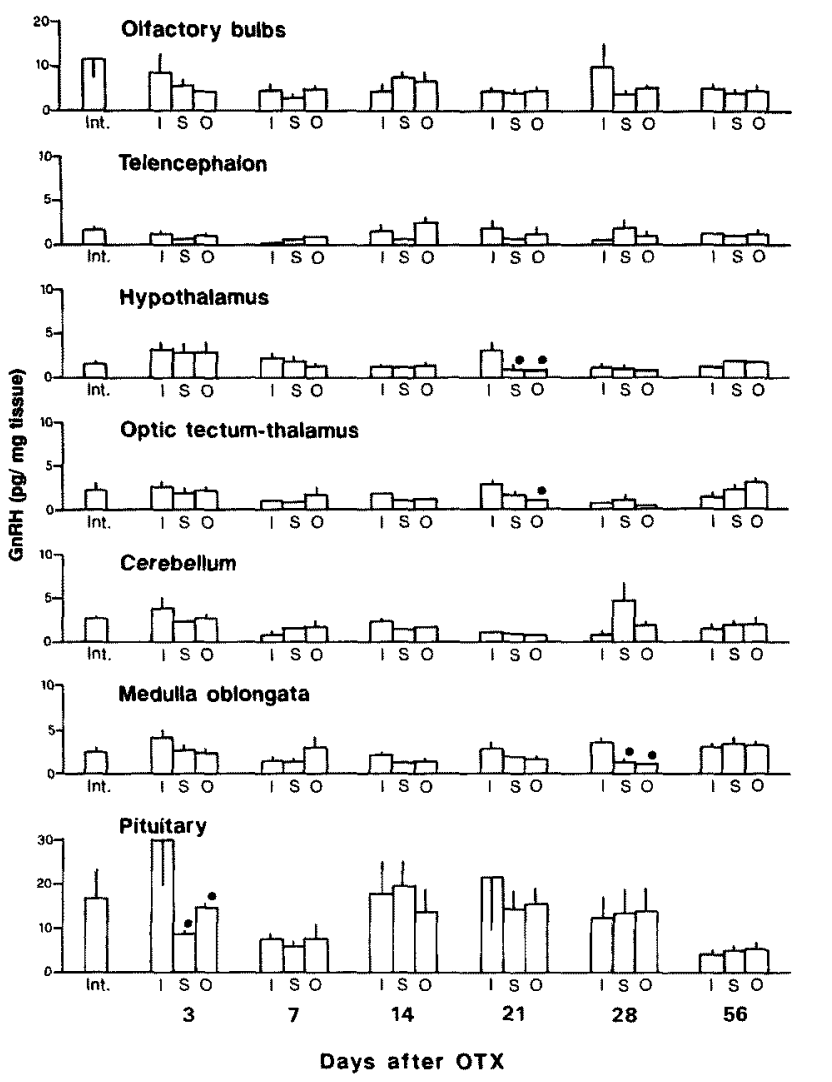

Fig. 4. Changes in cGnRH-II concentrations in discrete areas of the brain after olfactory tract section in female goldfish.

Int., initial control; $I$, intact; $S$, sham-operated fish; $O$, olfactory tract-sectioned fish. Each column represents the mean and SEM. $\bullet$, Difference compared to intact fish. Level of significance; $p<0.05$.

\section{Discussion}

Our previous studies reported a marked decrease in $s \mathrm{GnRH}$ contents in the brain of goldfish at one or two months after olfactory tract section. ${ }^{5,7}$ These long term experiments, however, did not show when and which of the various areas of the brain contributed to the decrease in sGnRH content. The present study traced changes in brain GnRH contents after olfactory tract section. Three days after the operation, sGnRH contents did not differ among three treatment groups. Salmon GnRH contents in OTX fish started to decrease at seven days after the operation, reached low levels at 14 days, and kept decreasing levels up to 56 days. The change in sGnRH observed in the present RIA study is in agreement with that observed in our immunocytochemical study in goldfish. ${ }^{10)}$ The density of sGnRH immunoreactive fibers in OTX fish started to decrease at seven days after the operation, and further diminished by 14 days. The exceptions were those in the preoptic area and anterior hypothalamus where the immunoreactive cell bodies are located. Considering the results of the immunocytochemical study, the small amount of sGnRH that remained after olfactory tract section observed in the RIA studies (Kobayashi et al. ${ }^{5,7)}$ and present study) is most likely due to sGnRH neurons in the preoptic area and anterior hypothalamus.
The present and previous investigation ${ }^{7}$ also suggest that there is no regeneration of TN-GnRH fibers for at least 56 days after olfactory tract section. Sham-operated fish exhibited a slight decrease in sGnRH levels after the operation probably due to some damage resulting from the operation.

It would appear that $\mathrm{TN}-\mathrm{sGnRH}$ cell bodies survive after OTX since the olfactory bulbs contain measurable amounts of sGnRH while other areas of the brain exhibited decreased levels. Salmon GnRH contents in the olfactory bulbs and the pituitary gland in the three treatment groups showed large variations and no clear tendencies which is consistent with our previous studies. ${ }^{5,7)}$ The cause of these large variations is not known.

No clear changes in contents of cGnRH-II in the brain could be detected for 56 days after the operation. Although an immunocytochemical study reported a slight decrease in cGnRH-II fibers, ${ }^{10)}$ our RIA studies did not detect similar changes. ${ }^{5,7}$ The difference between the studies is most likely due to the difference in sensitivities between the two different methods.

$\mathrm{Yu}$ and Peter ${ }^{11}$ reported a decrease in GnRH content in the brain only in the telencephalon three days after olfactory tract section in goldfish. The present study indicates that three days is insufficient to detect changes in brain GnRH after olfactory tract section in goldfish.

Since OTX fish are free from the influence of TN-GnRH neurons and the activity of other GnRH systems remain intact, OTX fish can serve as good models for investigating GTH release and brain GnRH activity. The present study indicates that the appropriate time for use of OTX fish is at 14 days or later after the operation. Since there seems no regeneration of sGnRH fibers up to two months after the operation (Kobayashi et al. ${ }^{7}$ and present study), OTX fish can be further subjected to long term treatments.

Acknowledgments This study was supported in part by Grants-in-Aid for Scientific Research from the Ministry of Education, Science, and Culture and by Grant-in-Aid (Bio Media Program BMP-94-II-2-9) from the Ministry of Agriculture, Forestry, and Fisheries. We thank Dr. C. S. Tamaru of Hawaii C's Aquaculture for his critical reading of the manuscript.

\section{References}

1) N. M. Sherwood, D. A. Lovejoy, and I. R. Coe: Origin of mammalian gonadotropin-releasing hormones. Endocrine Reviews, 14, 241-254 (1993).

2) R. K. Rostogi and L. Iela: Gonadotropin-releasing hormone: Present concepts, future directions. Zool. Sci., 11, 363-373 (1994).

3) O. Kah, I. Anglade, E. Lepretre, P. Dubourg, and D. de Monbrison: The reproductive brain. Fish Physiol. Biochem., 11, 85-98 (1993).

4) K. L. Yu, N. M. Sherwood, and R. E. Peter: Differential distribution of two molecular forms of gonadotropin-releasing hormone in discrete brain areas of goldfish (Carassius auratus). Peptides, 9, 625-630 (1988).

5) M. Kobayashi, M. Amano, Y. Hasegawa, and K. Aida: Effects of olfactory tract section on brain GnRH distribution, plasma gonadotropin levels, and gonadal stage in goldfish. Zool. Sci., 9, 765-773 (1992).

6) M.-H, Kim, Y. Oka, M. Amano, M. Kobayashi, K. Aida, and S. Kawashima: Immunocytochemical localization of $\mathrm{sGnRH}$ and cGnRH-II in the brain of goldfish, Carassius auratus. J. Comp. Neurol., 356, 72-82 (1995). 
7) M. Kobayashi, M. Amano, M. Kim, K. Furukawa, Y. Hasegawa, and $\mathrm{K}$. Aida: Gonadotropin-releasing hormones of terminal nerve orgin are not essential to ovarian development and ovulation in goldfish. Gen. Comp. Endocrinol., 92, 192-200 (1994).

8) K. Okuzawa, K. Amano, M. Kobayashi, K. Aida, I. Hanyu, Y. Hasegawa, and K. Miyamoto: Differences in salmon GnRH and chicken GnRH-II contents in discrete brain areas of male and female rainbow trout according to age and stage of maturity. Gen. Comp. Endocrinol., 80, 116-126 (1990).

9) M. Kobayashi, K. Aida, and I. Hanyu: Radioimmunoassay for sil- ver carp gonadotropin. Nippon Suisan Gakkaishi, 51, 1085-1091 (1985).

10) M. Kim, Y. Oka, M. Amano, M. Kobayashi, K. Aida, and S. Kawashima: Immunocytochemical localization of sGnRH and cGnRH-II in the goldfish brain and effects of olfactory tract section on the dustribution of GnRH. Proc. Japan Soc. Comp. Endocrinol., 8, 11 (1993).

11) K. L. Yu and R. E. Peter: Alterations in gonadotropin-releasing hormone immunoactivities in discrete brain areas of male goldfish during spawning behavior. Brain Res., 512, 89-94 (1990). 